\title{
Linking the upper crust to the upper mantle: comparison of teleseismic tomography with long-wavelength features of the gravity and magnetic fields of southeastern Australia
}

\author{
Robert Musgrave $^{1,3}$ Nicholas Rawlinson $^{2}$ \\ ${ }^{1}$ Geological Survey of NSW, Industry \& Investment NSW, PO Box 344, Hunter Region Mail Centre, \\ NSW 2310, Australia. \\ ${ }^{2}$ Research School of Earth Sciences, Australian National University Bldg 61, Mills Road, Acton, \\ ACT 0200, Australia. \\ ${ }^{3}$ Corresponding author. Email: robert.musgrave@industry.nsw.gov.au
}

\begin{abstract}
Acquisition of teleseismic data in south-western New South Wales during 2007 formed the latest stage of a rolling deployment of seismometers over south-eastern Australia, and allowed a revised tomographic model to be constructed for the lithospheric mantle under Victoria and southern NSW. Our aim here is to link the observed distribution of upper-mantle P-wave velocity to the major geological features of the upper crust, which here comprise terranes of the Delamerian and Lachlan orogens. We have extended the definition of the boundaries of these terranes under cover by the use of the tilt-filter of total magnetic intensity, which provides an image with detailed resolution for sources at depths down to $\sim 5 \mathrm{~km}$. We proceed to infer the distribution of deeper sources in the middle and lower crust by two approaches to the use of potential-field images: we exploit the relationship between wavenumber and source depth, through the application of a 20-km low-pass filter to the total magnetic intensity grid; and we take advantage of the lower sensitivity of gravity anomalies to depth of source, compared to magnetic anomalies with dipolar sources, by defining broad features in the isostatic gravity grid. Our interpretation of the lowpass magnetic and isostatic gravity imagery confirms the relationship between high mantle velocity and the Proterozoic Delamerian Orogen, and indicates that a salient of high mantle velocity under the Palaeozoic Stawell Zone results from an underthrust wedge of Delamerian basement. High mantle velocity under the Palaeozoic Wagga-Omeo Zone may be a result of lithospheric thickening that is a corollary of mid- to lower crustal thrust faulting indicated by the potential field data. Low mantle velocity under part of the Melbourne Zone may result from thermochemical resetting of its Proterozoic microcontinental basement by the thermal event responsible for the extensive Cainozoic volcanism in western Victoria; low mantle velocity under the Hay-Booligal Zone, which also appears to be anomalous, may similarly be related to a heat pulse that engendered the swarm of diatremes that is distributed across the zone.
\end{abstract}

Key words: depth-dependent imaging, isostatic gravity, layer filtering, long-wavelength anomalies, teleseismics, tilt-filter, tomography, total magnetic intensity.

\section{Introduction}

During 2007 the New South Wales (NSW) Department of Primary Industries contracted the Australian National Research Facility for Earth Sounding (ANSIR) to conduct the SEAL2 (South East Australia Linkage experiment, part 2) teleseismic program in south-western NSW. SEAL2 formed the next step in a rolling deployment of an array of short-period seismometers, with the eventual aim of complete, closely spaced coverage of southeastern Australia. Earlier phases of the program spanned Victoria, south-eastern South Australia, and part of the Murray Basin in NSW, and data from five surveys - LF98, MB99, EVA, SEAL1 and SEAL2 - have been processed to the point where they are ready for mantle velocity inversion (Figure 1). Central to this program is the question of the age of the underlying mantle lithosphere, and its relationship to tectonic terranes defined by surface geology and potential field data. The progressive eastwards decrease in basement age from Proterozoic to Phanerozoic across South Australia, Victoria and NSW should manifest either as an eastward decrease in P-wave velocity $\left(\mathrm{v}_{\mathrm{p}}\right)$ in the lithospheric mantle driven mainly by compositional differences (Griffin et al., 1998; Rawlinson et al., 2006a), or as a stepwise decrease in lithospheric thickness (Fishwick et al., 2008). Either scenario will result in a decrease in $v_{p}$ at depths of $\sim 150 \mathrm{~km}$. Complicating this simple pattern is the suggestion that isolated Proterozoic microcontinental fragments may constitute a deep crustal basement below parts of the Palaeozoic Lachlan Orogen of Victoria and NSW (Glen et al., 1992; Scheibner and Basden, 1998; VandenBerg et al., 2000; Betts et al., 2002; Cayley et al., 2002; Gray and Foster, 2004; Glen, 2005; Korsch, 2008).

Results of the earlier SEAL1 program (Rawlinson et al., 2006a), acquired with a seismic array in the southern Murray Basin, generally supported the expected eastward decrease in upper mantle $v_{p}$ from the Late Neoproterozoic to Cambrian Delamerian Orogen to the younger Lachlan Orogen, but appeared to conflict with recent interpretations of upper-crustal tectonic trends inferred primarily from aeromagnetic surveys in south-western NSW (Hallett et al., 2005), which suggest that the Stawell Zone of western Victoria continues northwards into NSW. Instead, the SEAL1 tomographic model suggested a break in upper mantle velocities near the state border; the model implied 


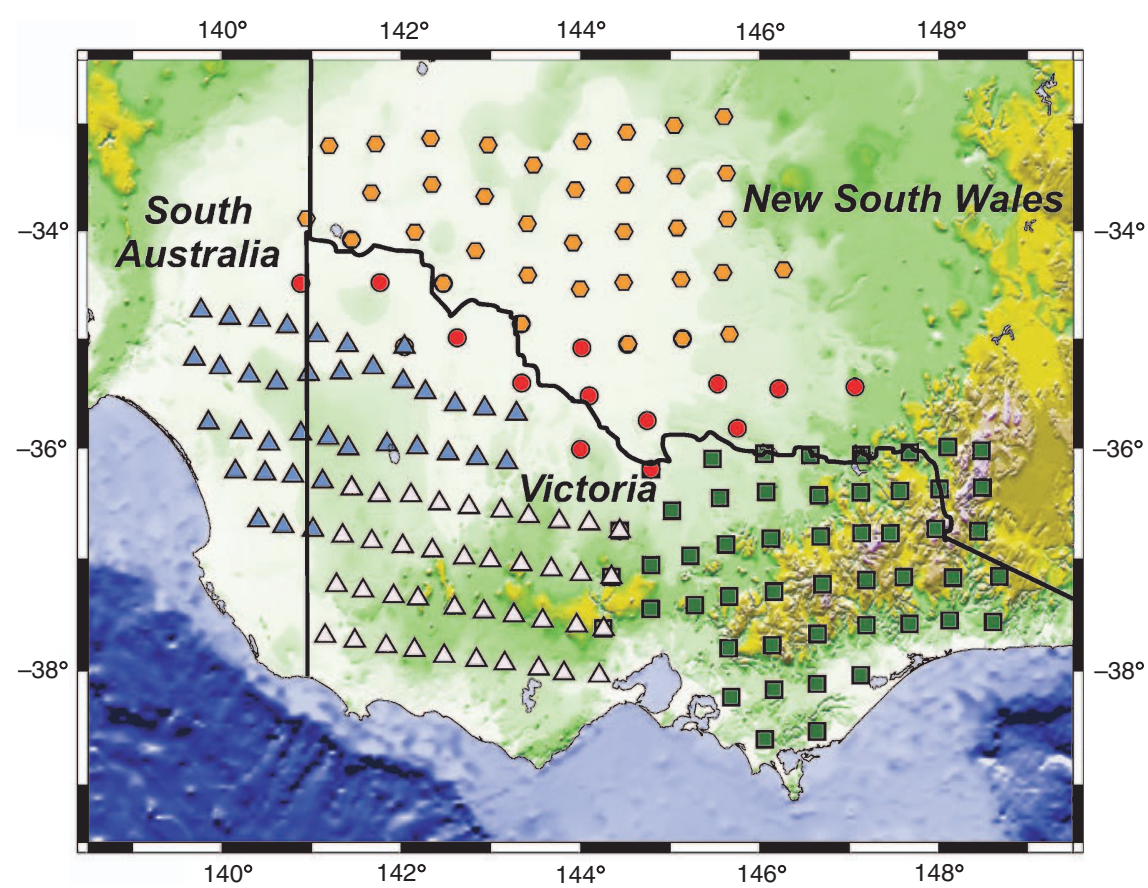

Fig. 1. Teleseismic survey locations in south-eastern Australia, shown on a digital elevation model for south-eastern Australia. Red circles - SEAL1; gold hexagons - SEAL2; white triangles - LF98; blue triangles - MB99; green squares - EVA.

that the Stawell Zone in Victoria is underlain by high $\mathrm{v}_{\mathrm{p}}$ upper mantle, consistent with lithospheric basement of Proterozoic age, while the putative extension of the Stawell Zone into NSW is underlain by low $\mathrm{v}_{\mathrm{p}}$ mantle, corresponding to Palaeozoic basement. In addition, the SEAL 1 model revealed two lobes of high $\mathrm{v}_{\mathrm{p}}$ upper mantle east of $145^{\circ} \mathrm{E}$ that lack a clear relationship to internal tectonic divisions within the Phanerozoic Lachlan Orogen.

Analysis of the SEAL2 dataset (Rawlinson et al., 2008) included a synthesis of all the processed south-east Australian teleseismic data into a single tomographic model of the upper mantle, which was both more extensive and better defined than the model inverted from the SEAL1 dataset alone (Figure 2). High $v_{p}$ upper mantle is imaged as a continuous belt in the Delamerian Orogen west of the Stawell Zone, and as an embayment under part of the Stawell and Bendigo zones in Victoria. The model also confirms the existence of high $\mathrm{v}_{\mathrm{p}}$ lobes east of $145^{\circ} \mathrm{E}$.

Resolution of any tomographic model is limited to a scale length equivalent to the station spacing, which for the south-east Australian surveys has typically been $50 \mathrm{~km}$. This limit precludes the tomographic model from being smoothly continued to the upper crust, where it could be directly compared with mappable geology. Consequently, it remains unclear whether inconsistencies between the distribution of mantle velocities and the bounding geometry of crustal tectonic terranes represent conflicts between crustal and mantle structure, or an oversimplified understanding of the influence of tectonic history on the temperature and composition of the upper mantle.

In this paper we investigate, and seek to resolve, the apparent discrepancy between the tomographic upper mantle models on the one hand, and the combination of mappable surface geology and interpreted upper-crustal geophysics on the other, by comparing both with geophysical and geological evidence that arises from sources located in the middle to lower crust. Potential field anomalies with wavelengths greater than $\sim 20 \mathrm{~km}$ should reveal middle crustal features, although the ability to distinguish them is compromised by the presence of broad anomalous sources (granitoids) in the upper crust, and, for the magnetic field, by suppression or corruption of long wavelengths during grid merging.

\section{Data and methods}

Teleseismic acquisition and processing for the SEAL2 array

Data acquisition in the SEAL2 program comprised deployment of 31 short-period (eigenfrequency $=1 \mathrm{~Hz}$ ) seismograph stations and five broadband seismograph stations between February and November 2007. Records were obtained from 187 earthquakes, mostly scattered around the seismogenic Asia-Pacific rim and with a few events from spreading centres in the South Atlantic and Indian oceans. At this stage of processing, only P-wave arrival times from the short-period stations have been considered. Preliminary alignment of the traces followed the ak135 global reference model (Kennett et al., 1995). An adaptive stacking technique (Rawlinson and Kennett, 2004) allowed extraction of a total of 5325 relative arrival-time residuals, which were inverted using the Fast Marching Teleseismic Tomography (FMTT) software package (Rawlinson et al., 2006b) to produce a tomographic model of upper mantle velocity. As a starting point for the inversion, a laterally invariant reference model was constructed by combining refraction velocities for the upper $50 \mathrm{~km}$ of the lithosphere (Collins, 1991) with the $a k 135$ model for mantle velocities below $50 \mathrm{~km}$ depth. Inversion produced a final model with a root mean square deviation from the data of $98 \mathrm{~ms}$, exceeding the estimated standard deviation of the noise by only $16 \mathrm{~ms}$; this remaining misfit can be attributed to unresolved variations in crustal structure, deep mantle structure below the local model volume, and velocity anisotropy. More detailed discussion of data acquisition, inversion, and resolution analysis is available in Rawlinson et al. $(2006 b, 2008)$. 


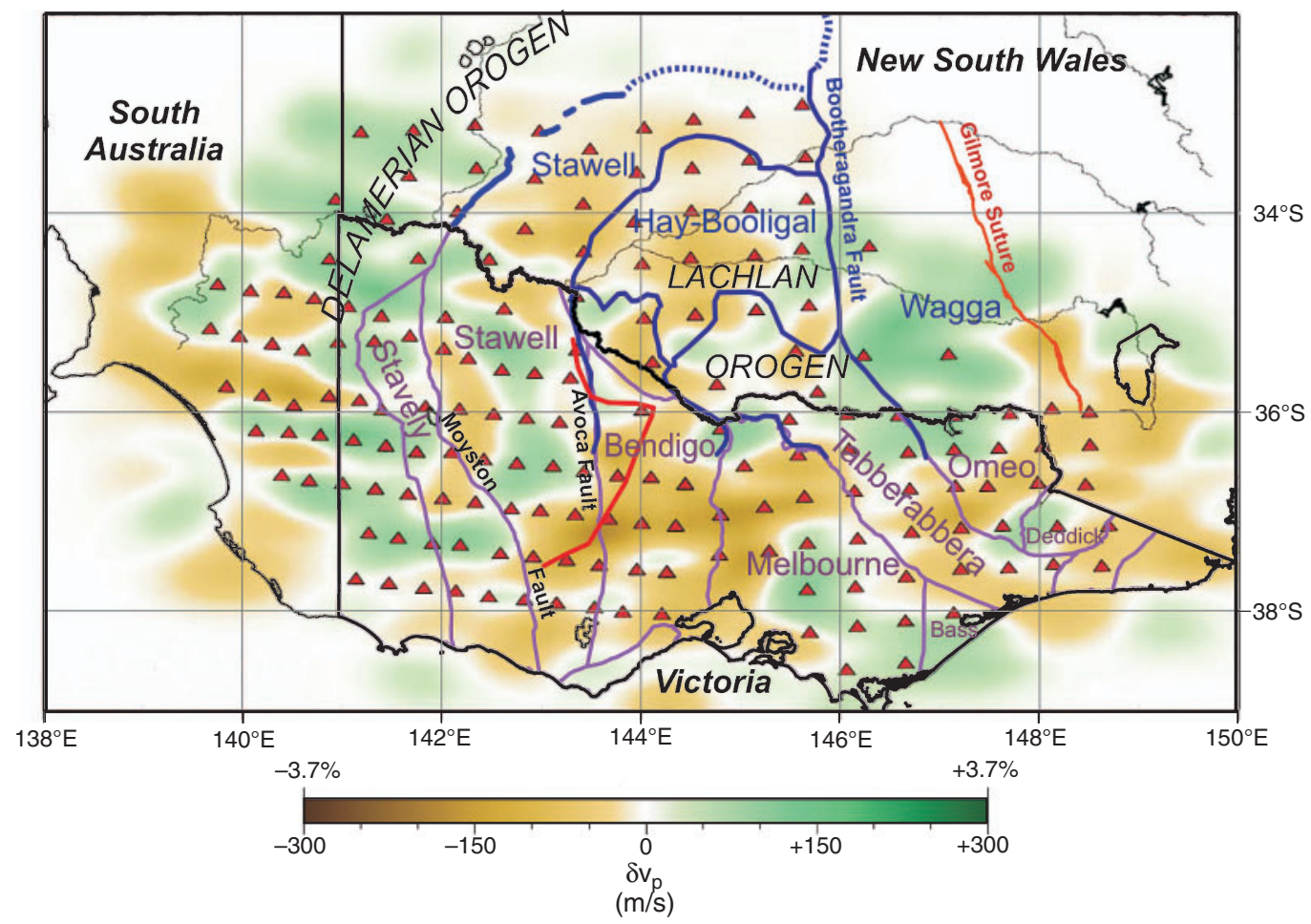

Fig. 2. Horizontal slice at $150 \mathrm{~km}$ depth through tomographic model generated as solution to the five processed teleseismic surveys from south-eastern Australia. Colour scale indicates $\mathrm{v}_{\mathrm{p}}$ variation from reference $a k 135$ model, shown as a proportion (upper scale) and in absolute terms (lower scale, in $\mathrm{m} / \mathrm{s}$ ): brown tones indicate anomalously slow mantle, green tones indicate anomalously fast mantle. State borders are shown in black. Boundaries of tectonic terranes defined on the basis of outcropping geology in Victoria are shown in purple: extensions of these boundaries below cover (largely based on interpretation of magnetic first vertical derivative images, after Hallett et al., 2005) are shown as continuous blue lines. Dashed blue lines indicate further extensions of terrane boundaries inferred from tilt-filtered total magnetic intensity (TMI) imagery (Musgrave et al., 2008). Orange line indicates surface trace of fault network comprising the Gilmore Suture. Red line divides strongly magnetic granites to the west from weakly magnetic granites to the east. Triangles are seismometer locations.

\section{Potential fields and depth-dependent imaging}

Wavelength filters, which exploit the inverse relationship between depth of source and the frequency content of the resulting potential field anomaly, are a core component of the geophysical support of geological mapping in areas of poor outcrop, and the means by which surface mapping is extended into three-dimensional inference. In particular, the first vertical derivative (1VD) of total magnetic intensity (TMI) is routinely used to map structure where non-magnetic cover is limited, typically less than $100 \mathrm{~m}$ (Boyd and Isles, 2007). Magnetic 1VD imagery, however, is of little help in extending mappable geological structure into the middle or lower crust. Deeper sources are more problematic to image, as the higher frequency components that define the edges of a source decline rapidly with increasing source-detector separation.

Recently, the Geological Survey of NSW has introduced the use of the tilt filter applied to gridded TMI data, to generate imagery in which structural elements down to a depth of a few kilometres can be discerned (Miller and Singh, 1994; Cooper and Cowan, 2006). The output of the tilt filter, applied to gridded TMI data after reduction to the pole, takes the form

$$
\theta=\tan ^{-1}\left(\frac{\partial T / \partial z}{\sqrt{\left((\partial T / \partial x)^{2}+(\partial T / \partial y)^{2}\right)}}\right)
$$

where $\theta$ is the tilt angle, over the domain $-\pi / 2<\theta<\pi / 2$, and $T$ is the intensity of the field. The tilt angle has the advantages of a wide dynamic range and a low sensitivity to source depth. Recent interpretation of the extension of the Stawell Zone to its limit where it abuts the Bootheragandra Fault (Figure 3) have been based on tilt-filter imagery (Musgrave et al., 2008); this is possible, even where the sedimentary cover exceeds $5 \mathrm{~km}$, as it does in the Yathong Trough (Hus et al., 2006).

Imaging structure in the middle to lower crust, below the useful range of the magnetic tilt-filter imagery, is more problematic. Layer filtering methods involve attenuation of wavenumbers corresponding to sources above or below the depth range of interest (Cowan and Cowan, 1993). In the case of gridded aeromagnetic data, where sub-crustal sources are removed as part of the geomagnetic reference field, this reduces to some form of low-pass filter. For our purposes, we ran a 20-km low pass filter over a 250-m grid merge of NSW and Victorian TMI.

Gravity images offer an alternative representation of crustal geology, which is inherently more focussed on the middle and lower crust than are unfiltered TMI images. In part, this is due to the lower sampling frequency of gravity (most gravity stations in NSW are spaced between 2 and $11 \mathrm{~km}$, whereas most of the state is covered by aeromagnetic data with an interline spacing of $400 \mathrm{~m}$ or better). However, even at equivalent sample spacing, and with an equivalent set of gravity and magnetic source bodies, deep sources will influence the gravity image more than the magnetic image. Broadly speaking, this is a result of the contrast in response between gravity sources, which are monopolar, and magnetic sources, which are dipolar if their z-dimension is finite. One expression of this behaviour is the structural index (SI) of Euler's equation, which can be seen as the exponent of the power law 


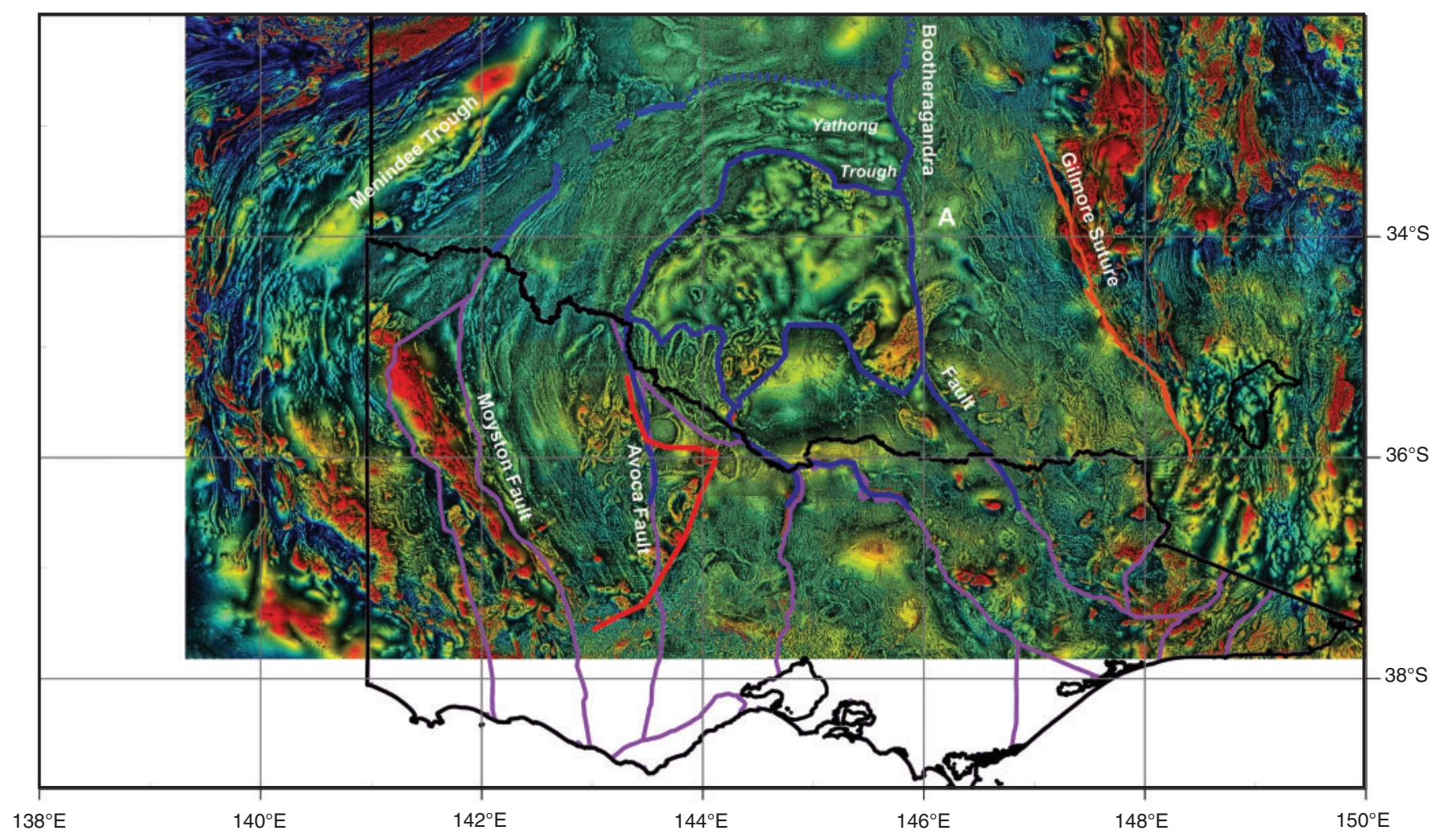

Fig. 3. Tilt-filtered total magnetic intensity (TMI), over same areas and with same symbols as Figure 2. Image comprises a pseudocolour TMI layer over a greyscale intensity tilt-angle layer. The letter 'A' marks a broad anomaly resulting from a deep source east of the Bootheragandra Fault that appears to represent a continuation of structure from the Hay-Booligal Zone.

expressing the rate of decline of field strength with distance from the source; for equivalent bodies, $\mathrm{SI}_{\text {gravity }}=\mathrm{SI}_{\text {magnetic }}-1$ (Stavrev, 1997; FitzGerald et al., 2004).

Isostatic reduction of Bouguer gravity removes the contribution from isostatically-controlled variations in crustal thickness, and the use of the ellipsoid as the elevation datum reduces the influence on the Bouguer anomaly of geoid responses to mantle mass excesses and deficits. As was the case for the magnetic data, the combination of isostatic reduction and the use of the ellipsoid datum effectively sets the base of the crust as the maximum limit to the depth of imaged sources.

\section{Descriptive comparison of datasets}

In order to trace the continuity - or lack thereof - of features through the lithosphere, we prepared a series of coincident images. Geological divisions in the upper crust are revealed by the tilt filter of TMI; upper mantle features are imaged by a slice of the $\mathrm{v}_{\mathrm{p}}$ tomographic model at $150 \mathrm{~km}$; and structures in the middle and lower crust which link these together should be visible in images of TMI with a 20-km low-pass filter and of isostatic gravity (Figures 4, 5).

\section{Upper crust}

Within Victoria, geological mapping can directly trace the extent of the north-trending Stawell Zone up to the point where the preMesozoic geology is buried below sediments of the Murray Basin. To the west, the Moyston Fault defines the boundary with the Stavely Zone, and the Avoca Fault provides the boundary between the Stawell Zone and the Bendigo Zone to the east. Aeromagnetic 1VD has been used to define the limits of the Stawell Zone north into NSW (Hallett et al., 2005), and the magnetic tilt-filter image suggests that the trace of the Moyston
Fault within the upper few kilometres of the crust continues along a broad curve to the east, eventually abutting the north-striking Bootheragandra Fault (Musgrave et al., 2008). Further south, the Bootheragandra Fault defines the eastern boundary of the Hay-Booligal and Tabberabbera zones. Some deeply sourced features in the tilt-filter image (for example, the roughly $40 \mathrm{~km}$ wide, low amplitude high marked by 'A' on Figure 3), which appear to be continuations of structures in the Hay-Booligal Zone, lie up to $50 \mathrm{~km}$ east of the short-wavelength signal of the surface trace of the Bootheragandra Fault, from which we infer a shallow eastwards dip for the fault. East of the Bootheragandra Fault, the Wagga-Omeo Zone extends from Victoria into NSW, where it is bounded on the east by the fault system comprising the Gilmore Suture (Stuart-Smith, 1991; Scheibner and Basden, 1996). Between the Bendigo and Tabberabbera zones lies the wedgeshaped Melbourne Zone, considered to be a veneer of Ordovician to Devonian upper crust underlain by a Proterozoic basement in the middle crust referred to as the Selwyn Block (VandenBerg et al., 2000).

\section{Upper mantle}

Low $v_{p}$ characterises most of the upper mantle between $142^{\circ} \mathrm{E}$ and $146^{\circ} \mathrm{E}$ in southern NSW and Victoria, and is flanked to the west by a north-south belt of higher $\mathrm{v}_{\mathrm{p}}$, broadly corresponding to the Delamerian Orogen (Figure 2). All of the Stawell Zone in NSW, and most of the Hay-Booligal zone is floored by low $\mathrm{v}_{\mathrm{p}}$ mantle, as is the southern part of the Stawell Zone and most of the Bendigo Zone in Victoria. North of the NSW-Victoria border, the inferred trace of the Moyston Fault in the upper crust forms the boundary between low $\mathrm{v}_{\mathrm{p}}$ upper mantle under the Stawell Zone and mostly high $v_{p}$ upper mantle to the north and west, although the definition of mantle velocity becomes poor north of the limits of the SEAL2 


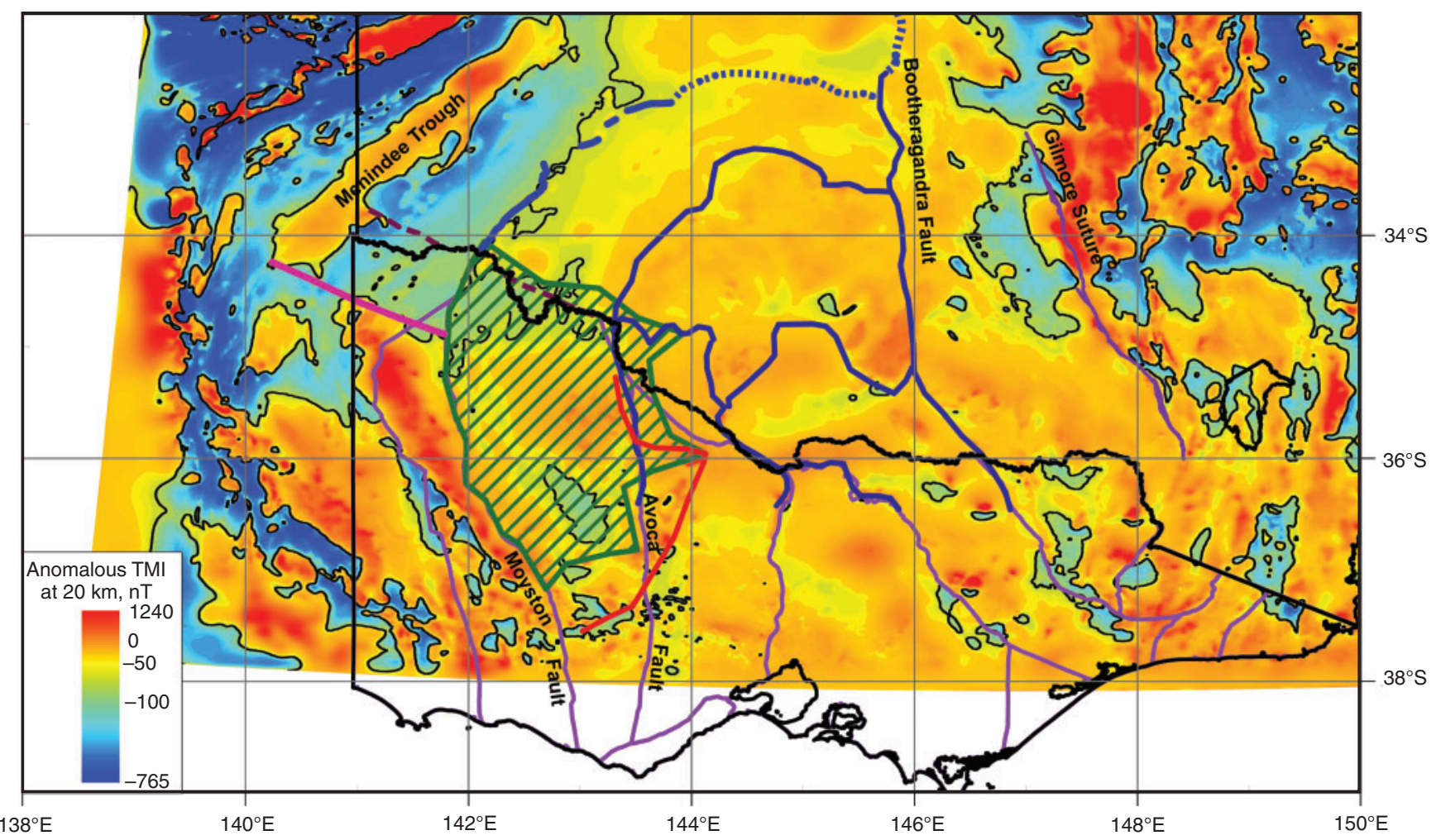

Fig. 4. Sun-shaded pseudocolour image of total magnetic intensity (TMI) after a 20-km low-pass filter, over same areas and with same symbols as Figure 2 . Contour line is arbitrary, but was chosen to correspond with a break in slope over both east and west flanks of the central high in southern New South Wales. Green shaded area encloses high $v_{p}$ salient under the Stawell and Bendigo zones seen in Figure 2. Pink line linking the southern end of the Menindee Trough to the Moyston Fault marks apparent left-lateral transform offset between the northern end of the magnetic high running along the axis of the Stavely Zone and the high in the Menindee Trough.

survey. South of the NSW-Victoria border, however, patches of high $\mathrm{v}_{\mathrm{p}}$ upper mantle extend from the west to define a salient below the Stawell zone; the leading edge of this feature cuts obliquely to the south-west across the Stawell Zone.

Further east, the surface trace of the Bootheragandra Fault roughly divides high $\mathrm{v}_{\mathrm{p}}$ upper mantle below the Wagga-Omeo Zone from the low $v_{p}$ upper mantle below the Hay-Booligal and Stawell zones, although the boundary is diffuse, and becomes poorly defined towards the north-eastern limit of the survey. High $\mathrm{v}_{\mathrm{p}}$ upper mantle occupies the southern half of the Melbourne Zone, as might be expected for mantle below the Proterozoic Selwyn Block, but mantle velocity decreases in the northern half of the zone, apparently at odds with the usual inference that the Selwyn Block extends under the entire Melbourne Zone (VandenBerg et al., 2000; Cayley et al., 2002).

\section{Middle to lower crust}

Total magnetic intensity shows a long-wavelength high approximately correlating with the central low mantle $\mathrm{v}_{\mathrm{p}}$ zone. To define the boundaries of this central magnetic high, we drew a contour of low-pass-filtered TMI set to a value which marks a break in slope on traverses across the high. This contour follows the trace of the northern extension of the Moyston Fault for $\sim 150 \mathrm{~km}$ north of the NSW-Victoria border. Beyond this point, the contour defining the edge of the long-wavelength magnetic high detaches from the boundary of the Stawell Zone and continues northward, although concentric textures within the broad magnetic high do follow the curving trend of the Stawell Zone. South of the NSW-Victoria border, inliers of lower TMI extend eastwards under the Stawell Zone, within the area spanned by the salient of high $\mathrm{v}_{\mathrm{p}}$ upper mantle.
Long-wavelength gravity over the Stawell Zone is relatively low between the Victoria-NSW border and $\sim 37^{\circ} \mathrm{S}$, defining an area roughly corresponding to the high $\mathrm{v}_{\mathrm{p}}$ salient and the low TMI inliers. North of the border, regional gravity within the Stawell Zone increases by $\sim 30 \mu \mathrm{ms}^{-2}$, the boundary marked by a wavelet edge that roughly matches the northern limit of the high $v_{p}$ salient and the northern edge of the low-TMI inliers.

On the eastern side of the central magnetic high, long wavelength magnetic and gravity anomalies match the upper mantle velocity distribution rather poorly. Both TMI and isostatic gravity decline to regional lows along the axis of the WaggaOmeo Zone, but the western edges of both the magnetic and gravity lows lie $\sim 30-80 \mathrm{~km}$ to the east of the Bootheragandra Fault, consistent with a shallow eastwards dip for the fault. Likewise, the eastern edge of the Wagga-Omeo magnetic and gravity lows lies $\sim 30 \mathrm{~km}$ west of the Gilmore Suture: in fact, magnetic and gravity anomalies representing mid-crustal elements of the Macquarie Arc (Glen et al., 2002) extend south-westwards across the surface trace of the Gilmore Suture. Evidently, this fault system dips westwards, and seismic reflection profiles support this (Glen et al., 2002). Isostatic gravity appears to be higher over the high- $\mathrm{v}_{\mathrm{p}}$ mantle in the southern part of the Melbourne Zone than over the low- $v_{p}$ mantle in the northern part of the zone. There is no evidence of structure in the low-pass TMI image corresponding to the division between the high and low $v_{p}$ mantle under the southern Melbourne Zone.

\section{Interpretation}

Deep crustal reflection seismic profiling across central Victoria indicates that the Stavely Zone underthrusts the Stawell Zone on an east-dipping Moyston Fault (Korsch, 2008). Rawlinson et al. 


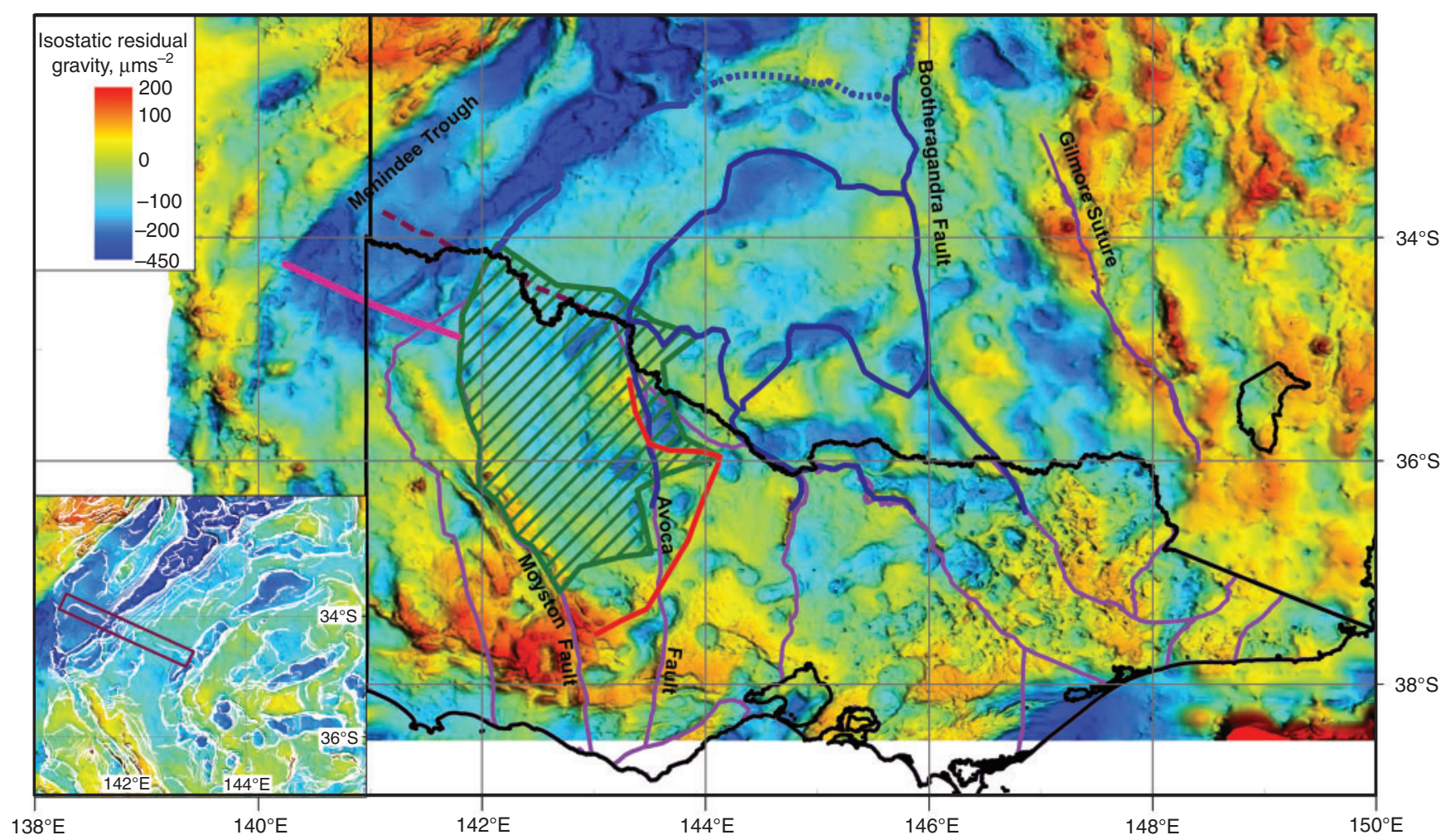

Fig. 5. Sun-shaded pseudocolour image of isostatically-reduced Bouguer gravity, over same areas and with same symbols as Figure 4. Isostatic reduction follows Spencer and Musgrave (2006), using an ellipsoid datum and spherical-cap version of the Bouguer correction (Bacchin et al., 2008). Inset map shows gravity wavelet edges ('worms'), shown as a series of white traces, derived from the same gravity data processed using the Intrepid WormE program package, and decimated by removing edges in the lowest $10 \%$ of the amplitude range. A prominent edge set extending from the Avoca Fault to the Menindee Trough, trending west-north-west across the locally dominant north-east trend, is shown in the inset map; a brown rectangle helps locate this feature. This same feature is shown on the main map as a dashed brown line that passes near the northern edge of the high $\mathrm{v}_{\mathrm{p}}$ embayment.

(2006a) suggested that fast, Proterozoic basement extended beneath the Stawell Zone. The geometry revealed by the tomographic model for the combined teleseismic arrays, and the correlating distribution of long-wavelength gravity and magnetic lows, suggests that the underthrust crust and mantle has a roughly triangular plan shape, with a sharp northern limit accommodated by a major transform fault, and with the extent of the thrust decreasing to the south, resulting in the oblique trend of the eastern boundary of the high $v_{p}$ salient. Intriguingly, the eastern boundary of the high $\mathrm{v}_{\mathrm{p}}$ region is paralleled, although offset southwards by $\sim 50 \mathrm{~km}$, by a line (shown in red on Figures 2-5) cutting obliquely across the Stawell and Bendigo zones, which separates strongly magnetic I-type granites to the west from weakly magnetic I-type and S-type granites to the east; the contrast between the two sets of granites is visible in the tiltfiltered TMI image. Granites are a feature of the upper crust whose chemistry - and hence, petrophysical properties - is controlled by their sources in the middle and lower crust (Chappell et al., 1988). White and Chappell (1988) recognised this boundary between magnetic and non-magnetic granite, which they ascribed to the contrast between oxidised granites having magnetite as a common accessory mineral in their 'Stawell Basement Terrane' to the west, and highly reduced ilmenite-bearing granites in their 'Melbourne Basement Terrane' to the east. Like the long-wavelength lows in the magnetic and gravity fields, the distribution of these magnetic granites presumably attests to the wedge of underthrust crust overlying the high $v_{p}$ mantle salient.

North of the high $\mathrm{v}_{\mathrm{p}}$ salient, the continuation of the Moyston Fault forms the boundary between mantle $\mathrm{v}_{\mathrm{p}}$ domains and, for part of its length, is also reflected in the magnetic signal originating in the middle to lower crust. We infer that this segment of the Moyston Fault is a steeply dipping, curved, left-lateral strike-slip fault, and that the concentric features within the northern part of the Stawell Zone reflect escape tectonics around an indentor constituted by the basement of the Hay-Booligal Zone (Figure 6). In this interpretation of the events of the Late Cambrian Delamerian Orogeny, the Stawell Zone was extruded when the Hay-Booligal microcontinent collided with a Cambrian arc comprising the Mount Wright arc and its southerly extension, which today is expressed as the deep magnetic sources beneath the Stavely Zone and the Menindee Trough (Musgrave et al., 2008). This geometry requires accommodation between the part of the Stavely Zone thrust under the Stawell Zone and its corresponding part which abuts the northern, strike-slip segment of the Moyston Fault. The accommodation zone is expressed as a $90-\mathrm{km}$ left-lateral offset between the prominent magnetic anomaly that occupies the northern part of the Stavely Zone and the corresponding deeply sourced anomaly under the Menindee Trough, and also marks the southern limit of a broad gravity low west of the northern part of the Moyston Fault.

High mantle velocity below the Wagga-Omeo Zone cannot easily be reconciled with the Phanerozoic age of the upper crust. Middle and lower crustal structure revealed by the lowpass TMI and isostatic gravity images suggest that the boundaries of this zone - the Bootheragandra Fault and Gilmore Suture - dip shallowly inwards towards the centre of the zone, forming low-angle thrusts that bound a wedge of metamorphosed, thrust-stacked marginal basin sediments 

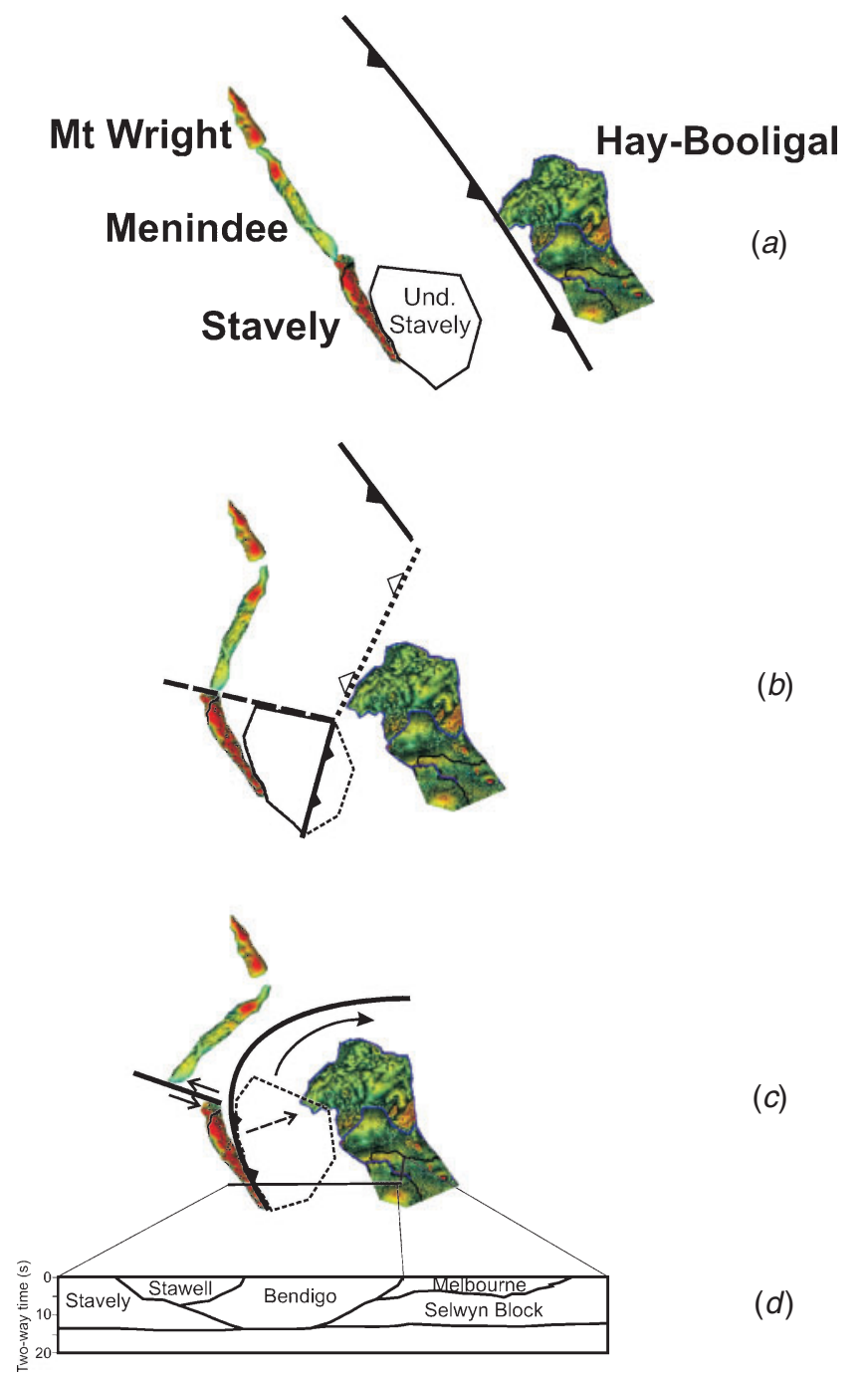

Fig. 6. Sketch showing summary of interpreted tectonic history of the Stawell Zone during the Delamerian Orogeny. Cut-outs of the tilt-filter image of Figure 3 show the Hay-Booligal Zone, and elements of a Cambrian volcanic arc comprising the Mount Wright arc, a series of deep magnetic sources under the Menindee Trough, and the deep magnetic sources under the Stavely Zone. Polygon marks former area of forearc in the Stavely Zone, now underthrust below the Stawell Zone and marked by the high $\mathrm{v}_{\mathrm{p}}$ salient. (a) Middle Cambrian subduction below Mount Wright-MenindeeStavely arc, continuing until (b) Hay-Booligal microcontinent collides with the arc in the Late Cambrian. Menindee segment of arc bends, and underthrusting of the Stavely Zone below the Stawell Zone commences. A transform fault between the Stavely and Menindee segments of the arc is initiated to accommodate the different responses to compression in the two segments. As the Delamerian Orogeny progresses (c), movement of the transform fault displaces the Stavely and Menindee segments of the arc, and underthrusting of the Stavely Zone continues. Stawell Zone sediments, caught between the Hay-Bolligal indentor and the arc segments, are expelled clockwise. The Moyston Fault acts as a thrust fault in Victoria, and has an increased component of left-lateral transcurrent motion in New South Wales. (d) Simplified interpretation of seismic section across central Victoria (Korsch, 2008), showing underthrust of Stavely Zone and the inferred position of the Selwyn Block.

(Scheibner and Basden, 1998). Higher mantle velocity beneath the zone may be indicative of localised lithospheric thickening related to this thrust system.

There is relatively little systematic correlation between structures imaged in the upper crust, middle to lower crust, and upper mantle over the Melbourne and Hay-Booligal zones. Only isostatic gravity appears to correlate with the distribution of mantle velocity below the Melbourne Zone, and the pattern of low $v_{p}$ corresponding to relatively lower gravity is the opposite of the relationship seen over the Stawell and Bendigo zones. Low mantle velocities under both the Melbourne and Hay-Booligal zones are unexpected, given the evidence for a Proterozoic basement below the Melbourne Zone (VandenBerg et al., 2000; Cayley et al., 2002; Korsch, 2008) and the inference that similar basement underlies the Hay-Booligal Zone (part of the 'Victorian Microcontinent' of Scheibner and Basden, 1998). Three possible mechanisms can be invoked to explain the inconsistency. Shallow thrusts and decollements may have stacked parts of these older crustal elements over younger mantle lithosphere; late Neoproterozoic rifting of these presumed microcontinental fragments may have reset their thermal and geochemical character; or later thermal and chemical modification of the lithospheric mantle may have been induced by rifting or mantle plume events. Evidence exists for thermal events with the potential to reduce upper mantle velocity under both the Melbourne and Hay-Booligal zones. Extensive Cenozoic volcanism in Victoria has been attributed to persistent after-effects of Tasman Sea and Australia-Antarctica rifting (Price et al., 2003), and may be responsible for the lower mantle velocity in the western part of the Melbourne Zone. More than 500 diatremes, buried by Murray Basin sediments and with a probable Late Permian age, form a swarm across the western Hay-Booligal Zone and the Stawell Zone near the NSW-Victoria border (Carlton, 2009); these presumably reflect a broad thermal source, possibly induced by a mantle plume.

\section{Conclusions}

Comparison of upper mantle seismic tomography with the interpretation of long-wavelength components of the magnetic and gravity fields allows us to examine the three-dimensional structure of the lithosphere. In the Stawell Zone, where the potential field imagery and mantle velocity model show a coherent spatial distribution, relatively simple thrust geometry can be inferred, and shown to have observable corollaries in seismic profiles and the distribution of magnetic granites. In other parts of the Lachlan Orogen, inconsistencies between upper crustal features, long-wavelength potential field anomalies, and the upper mantle velocity model, suggest a more complex three-dimensional structure than can be inferred directly from outcropping geology. High mantle velocity below the WaggaOmeo Zone may reflect lithospheric thickening associated with the thrust geometry of the boundaries of the zone. Thermal events may have modified Proterozoic basement below the Melbourne and Hay-Booligal zones, reducing mantle velocity.

\section{Acknowledgements}

This paper is published with the permission of the Director, Geological Survey of New South Wales, Industry \& Investment NSW. We gratefully acknowledge the constructive contributions of the reviewers.

\section{References}

Bacchin, M., Milligan, P., Tracey, R., and Wynne, P., 2008, New gravity anomaly grid and map of the Australian region: Preview, 136, 21-23.

Betts, P. G., Giles, D., Lister, G. S., and Frick, L., 2002, Evolution of the Australian lithosphere: Australian Journal of Earth Sciences, 49, 661-695. doi:10.1046/j.1440-0952.2002.00948.x

Boyd, D. M., and Isles, D. J., 2007, Geological interpretation of airborne magnetic surveys - 40 years on, in B. Milkereit, ed., Proceedings of Exploration 07: Fifth Decennial International Conference on Mineral Exploration, 491-505. 
Carlton, A., 2009, Carboniferous - Early Cretaceous? Volcanic plugs in the Balranald region, NSW: Australian Society of Exploration Geophysics and Petroleum Exploration Society of Australia, 20th International Geophysical Conference and Exhibition, Adelaide, 20-25 February 2009, Conference Handbook, abstracts, Preview February 2009, 55 .

Cayley, R., Taylor, D. H., VandenBerg, A. H. M., and Moore, D. H., 2002, Proterozoic-Early Palaeozoic tocks and the Tyennan Orogeny in central Victoria: the Selwyn Block and its tectonic implications: Australian Journal of Earth Sciences, 49, 225-254. doi:10.1046/j.14400952.2002.00921.x

Chappell, B. W., White, A. J. R., and Hine, R., 1988, Granite provinces and basement terranes in the Lachlan Fold Belt, southeastern Australia: Australian Journal of Earth Sciences, 35, 505-521. doi:10.1080/ 08120098808729466

Collins, C. D. N., 1991, The nature of the crust-mantle boundary under Australia from seismic evidence, in B. Drummond, ed., The Australian Lithosphere. Geological Society of Australia Special Publication, 17, $67-80$.

Cooper, G. R. J., and Cowan, D. R., 2006, Enhancing potential field data using filters based on the local phase: Computers \& Geosciences, 32, 1585-1591. doi:10.1016/j.cageo.2006.02.016

Cowan, D. R., and Cowan, S., 1993, Separation filtering applied to aeromagnetic data: Exploration Geophysics, 24, 429-436. doi:10.1071/ EG993429

Fishwick, S., Heintz, M., Kennett, B. L. N., Reading, A. M., and Yoshizawa, K., 2008, Steps in lithospheric thickness within eastern Australia, evidence from surface wave tomography: Tectonics, 27, TC4009. doi:10.1029/2007TC002116

FitzGerald, D., Reid, A., and McInerney, P., 2004, New discrimination techniques for Euler deconvolution: Computers \& Geosciences, 30, 461-469. doi:10.1016/j.cageo.2004.03.006

Glen, R. A., 2005, Tasmanides of eastern Australia, in A. P. M. Vaughan, P. T. Leat and R. J. Pankhurst, eds, Terrane Processes at the Margins of Gondwana, Geological Society, London, 246, 23-96.

Glen, R. A., Scheibner, E., and VandenBerg, A. H. M., 1992, Paleozoic intraplate escape tectonics in Gondwanaland and major strike-slip duplication in the Lachlan orogen of southeastern Australia: Geology, 20, 795-798. doi:10.1130/0091-7613(1992)020<0795:PIETIG $>2.3$. $\mathrm{CO} ; 2$

Glen, R. A., Korsch, R. J., Direen, N. G., Jones, L. E. A., Johnstone, D. W., Lawrie, K. C., Finlayson, D. M., and Shaw, R. D., 2002, Crustal structure of the Ordovician Macquarie Arc, Eastern Lachlan Orogen, based on seismic-reflection profiling: Australian Journal of Earth Sciences, 49, 323-348. doi:10.1046/j.1440-0952.2002.00925.x

Gray, D. R., and Foster, D. A., 2004, Tectonic evolution of the Lachlan Orogen, southeast Australia: historical review, data synthesis, and modern perspectives: Australian Journal of Earth Sciences, 51, 773-817. doi:10.1111/j.1400-0952.2004.01092.x

Griffin, W. L., O'Reilly, S. Y., Ryan, C. G., Gaul, O., and Ionov, D. A., 1998, Secular variation in the composition of subcontinental lithospheric mantle: geophysical and geodynamic implications, in J. Braun, J. Dooley, B. Goleby, R. van der Hilst and C. Klootwijk, eds, Structure and Evolution of the Australian Continent, Geodynamics Series, 26, American Geophysical Union, Washington, D.C., U.S.A., $1-26$.

Hallett, M., Vassallo, J., Glen, R., and Webster, S, 2005, Murray-Riverina region: an interpretation of bedrock Palaeozoic geology based on geophysical data: Geological Survey of New South Wales, Quarterly Notes, 118, 1-16.
Hus, R., Pryer, L., and Petrovich, S., 2006, Murray-Darling-Eromanga Infill SEEBASE ${ }^{\mathrm{TM}}$ and Structural GIS Project: Addendum to the Darling Basin SEEBASE ${ }^{\mathrm{TM}}$ Project: Report to NSW Department of Primary Industries by FrOG Tech Pty Ltd.

Kennett, B. L. N., Engdahl, E. R., and Buland, R., 1995, Constraints on seismic velocities in the Earth from travel times: Geophysical Journal International, 122, 108-124. doi:10.1111/j.1365-246X.1995.tb03540.x

Korsch, R., 2008, Central Victorian deep seismic survey: Preview, 134, 28-29.

Miller, H. G., and Singh, V., 1994, Potential field tilt - a new concept for location of potential field sources: Journal of Applied Geophysics, 32, 213-217. doi:10.1016/0926-9851(94)90022-1

Musgrave, R. J., Hallett, M., Carlton, A., and Poudjom Djomani, Y., 2008, New geophysical constraints on the extent of the Stawell and Bendigo zones in New South Wales: abstracts, Australian Earth Sciences Convention, Perth, Western Australia, 20-24 July 2008.

Price, R. C., Nicholls, I. A., and Gray, C. M., 2003, Cainozoic igneous activity, in W. D. Birch, ed., Geology of Victoria, Geological Society of Australia Special Publication, 23, 361-375.

Rawlinson, N., and Kennett, B. L. N., 2004, Rapid estimation of relative and absolute delay times across a network by adaptive stacking: Geophysical Journal International, 157, 332-340. doi:10.1111/j.1365-246X.2004. 02188.x

Rawlinson, N., Kennett, B. L. N., and Heintz, M., 2006a, Insights into the structure of the upper mantle beneath the Murray Basin from 3D teleseismic tomography: Australian Journal of Earth Sciences, 53, 595-604. doi:10.1080/08120090600686751

Rawlinson, N., Reading, A. M., and Kennett, B. L. N., 2006b, Lithospheric structure of Tasmania from a novel form of teleseismic tomography: Journal of Geophysical Research, 111, B02301. doi:10.1029/ 2005JB003803

Rawlinson, N., Robson, D., and Glen, R.A., 2008, Deep structure beneath the Murray Basin from teleseismic tomography: Geological Survey of New South Wales, Quarterly Notes, 129, 1-14.

Scheibner, E., and Basden, H., 1996, Geology of New South Wales Synthesis, Volume 1, Structural Framework, Geological Survey of New South Wales, Memoir Geology, 13(1).

Scheibner, E., and Basden, H., 1998, Geology of New South Wales Synthesis, Volume 2, Geological Evolution, Geological Survey of New South Wales, Memoir Geology, 13(2).

Spencer, R., and Musgrave, R. J., 2006, Isostatic and decompensative correction of gravity data from New South Wales: Exploration Geophysics, 37, 210-214. doi:10.1071/EG06210

Stavrev, P. Y., 1997, Euler deconvolution using differential similarity transformations of gravity or magnetic anomalies: Geophysical Prospecting, 45, 207-246. doi:10.1046/j.1365-2478.1997.00331.x

Stuart-Smith, P. G., 1991, The Gilmore Fault Zone-the deformational history of a possible terrane boundary within the Lachlan Fold Belt, New South Wales: BMR Journal of Australian Geology and Geophysics, 12, 35-49.

VandenBerg, A. H. M., Willman, C. E., Maher, S., Simons, B. A., Cayley, R. A., Taylor, D. H., Morand, V. J., Moore, D. H., and Radojkovic, A., 2000, The Tasman Fold Belt System in Victoria, Geological Survey of Victoria Special Publication.

White, A. J. R., and Chappell, B. W., 1988, Granites, in J. G. Douglas and J. A. Ferguson, eds, Geology of Victoria, Geological Society of Australia, Victorian Division, 427-439.

Manuscript received 15 May 2009; revised manuscript accepted 16 February 2010. 